\title{
Bacteriological investigation on "Mauro" sold in Catania
}

\author{
G. Ziino • V. Nibali • A. Panebianco
}

Published online: 14 May 2010

(C) Springer Science+Business Media B.V. 2010

\begin{abstract}
Seaweeds known as "Mauro" are traditionally used fresh or to prepare omelettes in Sicily (Italy). Twenty samples sold in Catania between May 2005 and September 2007 were analyzed for Escherichia coli, Total Enterobacteria, Aeromonas spp., Pseudomonas spp., Vibrio spp., and Salmonella spp. Thirty Vibrio strains were examined for the presence of the virulence genes, toxR, toxRS, tl, tdh, and trh in the genomes of the isolates. Total Enterobacteria ranged between 2.23 and $6.85 \mathrm{log} \mathrm{CFU} / \mathrm{g}$, and in six samples, E. coli ranged between 0.70 and $2.74 \log \mathrm{CFU} / \mathrm{g}$. Aeromonas spp. was present in samples between 1.0 and $5.90 \log$ CFU/g, while Pseudomonas spp. ranged between 2.70 and $7.27 \log$ CFU/g. Vibrio spp. was present in $75 \%$ of samples at values between 1.30 and $4.60 \log \mathrm{CFU} / \mathrm{g}$. The most frequently isolated species was $V$. alginolyticus $(76.66 \%$ of isolates), of which $82.60 \%$ were positive for toxR and the remaining $17.40 \%$ of strains were positive for toxRS. $V$. parahaemolyticus was identified in $13.33 \%$ of strains; all were positive for toxR and, in one case, for both toxR and toxRS. V. coralliitycus was isolated in $6.66 \%$ of strains (all positive for toxR), and one was identified as $V$. mimicus (positive for toxRS). The results of this study suggest that there is need for stringent quality control during harvesting and distribution of Mauro.
\end{abstract}

Keywords Mauro · Seaweed · Halophilic Vibrio · Virulence properties · Food hygiene

$\begin{array}{ll}\text { Abbreviations } \\ \text { CFU } & \text { colony forming units } \\ \text { PCR } & \text { polymerase chain reaction } \\ \text { TCBS } & \text { thiosulfate citrate bile salt sucrose agar } \\ \text { TBX } & \text { Tryptone Bile X-glucuronide medium } \\ \text { XLD } & \text { Xylose Lysine Deoxycholate agar } \\ \text { tdh } & \text { thermostable direct haemolysin } \\ \text { trh } & \text { TDH-related hemolysin } \\ \text { tl } & \text { thermolabile hemolysin }\end{array}$

G. Ziino $(\bowtie) \cdot$ V. Nibali $\cdot$ A. Panebianco

Dipartimento di Sanità Pubblica Veterinaria, Facoltà di Medicina Veterinaria,

Università degli Studi di Messina, Polo Universitario Viale Annunziata, 98168 Messina, Italy

e-mail: gziino@unime.it 


\section{Introduction}

For centuries, seaweed has been an important food in the culinary traditions of several coastal populations in Asia, particularly in China, Korea, and especially Japan, where the consumption of $1.6 \mathrm{~kg}$ (dry weight) per years per capita has been recorded (FujiwaraArasaki et al. 1984). Laminaria japonica, Porphyra tenera, Undaria pinnatifida, Eisenia bicyclis, and Ulva lactuca are just some of the species that are normally eaten raw, dried, and as a condiment in soups or drinks. However, their culinary use has been noted in many other countries. For example, before the Spanish conquest of Mexico, the Aztecs used Spirulina maxima (Tecuitlat), which is found in Lake Texcoco; S. fusiformis is eaten in India; the people in Ciad take S. platensis from Lake Kossorom, which is filtered and dried (dihè) and used for the preparation of meat and soup. In different European countries, the consumption of "sea greens" (Ulva lactuca) was common. France has recently discovered such traditions, and in 1988 officially authorized 12 species of seaweed for human consumption, including Chondrus crispus, which is included in the ingredients of a famous milk pudding (blanc manger). In Great Britain, fritters are made from fresh sea lettuce, which is reduced to a puree and mixed with oatmeal. In Ireland, Palmaria palmata and Dilsea edulis are used fresh in salads, while in Norway, "black butter" is prepared using boiled algae. Dishes based on seaweed are found in many Italian coastal areas. For example, in the province of Palermo (Sicily), Nemalion helminthoides, known as "Turkish spaghetti," is eaten, while Hypnea musciformis is used in southeastern Sicily (Lentini and Venza 2007). The names "Mauru impiriali," "Mauru a ciuffu longu," "Mauru a ciuffu curtu," "Mauru rizzu," and "curaddina" commonly indicate "Mauro," a seaweed that is particularly popular in the provinces of Syracuse, Messina, and, especially, Catania (Nicotra 1960). The most important species that can be categorized as "Mauro" are Chondrus crispus, Calliblepharis jubata, Grateloupia filicina, Chondracanthus acicularis, and Chondracanthus teedii, which have been often incorrectly identified in some Sicilian dictionaries. The term "Mauro" appeared for the first time in 1838 in a Sicilian dictionary by Mortillaro (1838), where it was mistakenly defined as "fuco commestibile," thus creating the belief that it belongs to the Fucaceae family. The same definition was reported by Traina in 1868 and by Nicotra D'Urso in 1914. Even older is the term "curaddina" indicated by Del Bono (1751) as "Curallina cordiali," which in this case mistakenly leads one to think of Corallina officinalis. According to Nicotra (1960), the species consumed in Sicily would be more correctly identified as Chondracanthus teedii (or Gigartina teedii). However, both would be commonly associated due to their anti-helminth properties. The first four species are preferred cooked, fried in hot oil, while curaddina, because of its flavor, fragrance, and tender consistency, is eaten fresh with perhaps a little fresh lemon juice or vinegar and a pinch of salt. Curaddina can be many different colors, from scarlet to a bluish red or green and grows quickly; it is often gathered every 4 days from a depth ranging between 1 and 4 meters, preferably on a rocky seabed, from the end of November to the beginning of September. There is a high demand for curaddina in the summer months and during local festivities. Traditionally, seaweed was torn by hand and placed carefully in sacks on the seabed for harvesting. In the winter, it was gathered by boat by raking the seabed with a long "fork." As soon as it was gathered, the Mauro was washed with seawater and sold on the streets from stalls specifically assembled for this purpose, from fishmongers who dressed the Mauro with lemon juice and salt and served it on paper plates, or occasionally in restaurants. Based on what has already been recorded from the discovery of old local traditions, the aim of this work is to investigate the hygienic quality of Mauro sold in the city of Catania. 


\section{Materials and methods}

The study was carried out on 20 samples of Mauro sold by fishmongers or from street stalls in Catania between May 2005 and September 2007. All samples were transported for $1 \mathrm{~h}$ at a refrigerated temperature to the laboratory to be processed for the following bacteriological determinations: i) Escherichia coli plated onto $\mathrm{TBX}$ (Oxoid) $\left(37^{\circ} \mathrm{C} \times 24 \mathrm{~h}\right)$; ii) total Enterobacteria plated onto violet red bile agar (Oxoid) $\left(37^{\circ} \mathrm{C} \times 24 \mathrm{~h}\right)$; iii) Aeromonas spp. plated on GSP (Merck) plus penicillin $\left(30^{\circ} \mathrm{C} \times 24 \mathrm{~h}\right)$; iv) Pseudomonas spp. plated on Pseudomonas agar base (Oxoid) $\left(30^{\circ} \mathrm{C} \times 24 \mathrm{~h}\right)$; and v) Vibrio spp. plated on thiosulfate citrate bile salt sucrose agar (TCBS) (Oxoid) with $3 \% \mathrm{NaCl}\left(37^{\circ} \mathrm{C} \times 24 \mathrm{~h}\right)$. Thirty colonies grown on TCBS were subjected to phenotypic identification as described by Ottaviani et al. (2003). All strains that were Gram- and oxidase positive, with a typical growth on Kliger iron agar (Oxoid) and capable of developing in the presence of $3 \% \mathrm{NaCl}$, were preliminarily subjected to biomolecular analysis using specific primers for Vibrio spp. as described by La Neve et al. (2006), and then to successive biochemical species identification described by Noguerola and Blanch (2008). Finally, multiplex PCR was performed for the presence of different virulence genes (ToxR, ToxRS, tl, tdh, and trh), according to the procedures described by Bej et al. (1999) and Xie et al. (2005). Amplimers were resolved by electrophoresis on a $1.5 \%$ agarose gel for $50 \mathrm{~min}$ at $110 \mathrm{~V}$ and stained with ethidium bromide for $20 \mathrm{~min}$. The samples were tested for Salmonella spp. after a preenrichment in buffered peptone water $\left(35^{\circ} \mathrm{C} \times 18-24 \mathrm{~h}\right)$ and following enrichment in Rappaport-Vassiliadis enrichment broth (Oxoid) $\left(42^{\circ} \mathrm{C}\right.$ for $\left.24-48 \mathrm{~h}\right)$ and in selenite broth base (Oxoid) $\left(35^{\circ} \mathrm{C} \times 18-24 \mathrm{~h}\right)$. After the incubation, the cultures were streaked on XLD (Oxoid) and incubated at $37^{\circ} \mathrm{C}$ for $24 \mathrm{~h}$. Suspicious colonies were biochemically evaluated using the Api 20E system (BioMérieux).

\section{Results}

The examined samples were sometimes identified as Chondrus crispus (Mauru impiriali) or Chondracanthus teedii (curaddina) and more frequently a mixture of both. The seaweed had a pleasant salty smell, a strong clear color, and was never slimy. For all samples, the precise area of origin was never known. With regard to the bacteriological analyses, Enterobacteria contaminated all seaweed samples at 2.23-6.85 log CFU/g; in six samples, E. coli was present at $0.70-2.74 \log$ CFU/g. Vibrio spp. was present in $75 \%$ of samples at $1.30-4.60 \log \mathrm{CFU} / \mathrm{g}$. The most frequently isolated species was V. alginolyticus ( $76.66 \%$ of isolates) of which $82.60 \%$ were positive for genes encoding factor ToxR and the remaining $17.40 \%$ possessed genes encoding ToxRS. V. parahaemolyticus was identified in $13.33 \%$ of the strains; all were positive for ToxR and, in one case, for both ToxR and ToxRS. $V$. coralliitycus was isolated in $6.66 \%$ of the strains (all positive for ToxR), and one was identified as $V$. mimicus, which was positive for ToxRS. Aeromonas spp. was present at 1.0-5.90 logs CFU/g, while Pseudomonas spp. ranged from 2.70 to $7.27 \operatorname{logs} \mathrm{CFU} / \mathrm{g}$.

\section{Discussion}

The results highlight the extreme bacteriological variability of Mauro. The hygienicsanitary profile revealed contamination from total Enterobacteria in different samples and 
the presence of potentially pathogenic species, such as Vibrio spp. and Aeromonas spp., which is worrisome in a food that is eaten raw. Such results differ greatly from those shown by Karacalar and Turan (2008) in samples of Ulva lactuca sold in Turkey, in which both Vibrio spp. and coliforms were slightly above the value of $4.0 \mathrm{CFU} / \mathrm{g}$ or from similar investigations carried out in France, Sweden, and Japan in which coliform values ranged between 10-100 $\mathrm{CFU} / \mathrm{g}$. It has been noted that numerous factors can affect the adhesion of bacteria to the surfaces of seaweed as well as the degree of anthropic contamination in the environment of origin. Due to a lack of information regarding the area where the examined samples were gathered, we can only hypothesize about what has already been described for Anemonia sulcata (Ziino et al. 2008). The fact that the sampling was performed during the hot season, together with anthropic contamination caused by swimmers could have affected the bacteriological levels. Furthermore, it cannot be ruled out that cross contamination could also have occurred during handling.

It is important to also highlight that, as already demonstrated by Paull and Jung Chen (2007) in samples of farmed Gracilaria sp., seaweed represents a subsurface onto which bacteria are able to multiply quickly at room temperature. Consistent with what has already been shown by other authors (Xie et al. 2005), it is interesting to highlight the large distribution of ToxR and ToxRS pathogenicity factors in both V. parahaemolyticus and other species, which could represent an important reservoir of virulence genes in the aquatic environment. Therefore, we believe that with the aim of safeguarding an old popular tradition, it is necessary to ensure acceptable safety levels for the consumer. For this purpose, it is necessary to thoroughly wash the seaweed to remove sediment and other foreign materials and keep it at a refrigerated temperature, which integrates well with Annex 1, Part A of Regulation (EC) 852/2004 concerning the primary production of foods of animal or vegetable origin to meet the minimal safety requirements stipulated by the European Community.

\section{References}

Bej AK, Patterson DP, Brasher CW, Vichery MCL, Jones DD, Kaisner CA, (1999) Detection of total and hemolysin-producing Vibrio parahaemolyticus in shellfish using mPCR amplification of $\mathrm{tl}$, tdh and trh. J Microbiol Methods 36:215-225

Del Bono M (1751) Dizionario siciliano-italiano-latino. Stamperia Gramignani, Palermo

Fujiwara-Arasaki T, Mino N, Kuroda M (1984) The protein value in human nutrition of edible marine algae in Japan. Hydrobiologia 116/117:513-516

Karacalar U, Turan G (2008) Microbiological assays on edible seaweed Ulva Lactuca (L.) cultured in outdoor tanks. JABS 2:27-30

La Neve F, Pedonese F, Nuvoloni R, D’Ascenzi C, Dalmasso A, Civera T (2006) Identificazione di Vibrioni di interesse sanitario in orate di allevamento mediante metodiche biomolecolari. Atti Società Italiana delle Scienze Veterinarie 60L431-432

Lentini F, Venza F (2007) Wild food plants of popular use in Sicily. J Ethnobiol Ethnomed 30:3-15

Mortillaro V (1838) Nuovo dizionario siciliano italiano. P Pensante, Palermo

Nicotra G (1960) Il mauru ossia alghe rosse commestibili nella Sicilia centro-orientale. Tipografia CITEM, Catania

Nicotra D’Urso E (1914) Nuovissimo dizionario siciliano-italiano. La Siciliana, Catania

Noguerola I, Blanch AR (2008) Identification of Vibrio spp. with a set of dichotomous keys. J Appl Microbiol 105:175-185

Ottaviani D, Masini L, Bacchiocchi S (2003) A biochemical protocol for the isolation and identification of current species of Vibrio in seafood. J Appl Microbiol 95:1277-1284

Paull RE, Jung Chen N (2007) Postharvest handling and storage of the edible red seaweed Gracilaria. Postharvest Biol Technol 48:302-308 
Traina A (1868) Nuovo vocabolario siciliano italiano, Finocchiaro, Palermo

Xie ZY, Hu CQ, Chen C, Zhang LP, Ren CH (2005) Investigation of seven Vibrio virulence genes among Vibrio alginolyticus and Vibrio parahaemolyticus strains from the coastal mariculture systems in Guangdong, China. Lett Appl Microbiol 41:202-207

Ziino G, Donato G, Panebianco A (2008) Riscontri batteriologici in Anemonia sulcata (Pennant, 1977). Atti Società Italiana delle Scienze Veterinarie 62:417-418 